\title{
VoterMedia as Participatory Budgeting
}

\author{
Mark Latham* \\ February 21, 2012 \\ Future revisions at votermedia.org/publications
}

\begin{abstract}
This paper compares two experimental models for participatory budgeting: the model pioneered by the city of Porto Alegre, Brazil; and the "votermedia" blog competitions implemented at the University of British Columbia and at several municipalities in Metro Vancouver, Canada. The mainstream Porto Alegre participatory budgeting (PAPB) model is well documented elsewhere, so more detailed descriptions are given here for votermedia.

Votermedia is designed primarily to fund voter information. PAPB typically funds a range of municipal services, not including voter information. Votermedia is more competitive and entrepreneurial, with open entry for various potential providers, who may make a profit or a loss. With PAPB, the voter-selected services are provided by municipal employees with specified budgets. The system for voting funds in votermedia can be seen as an extension of PAPB-style voting, to further empower citizens to determine the size of each budget slice. Votermedia blog competitions can cost as little as $\$ 8,000$; PAPB processes generally involve much larger budgets.

The changing economics of media have strengthened the case for government funding of public interest journalism, especially at the municipal level. Votermedia is proposed as a cost-effective way to enhance citizen engagement and information in a PAPB process. This would ideally include a continuous-time blog contest with online voting that starts at the beginning of the budget's public consultation stage. Blogs could also be rewarded via a competitive vote on the same ballot when citizens are choosing which projects to fund from the participatory budgeting finalists menu; and/or votermedia could be one of the candidate projects to fund going forward.

The potential future evolution of participatory budgeting including votermedia is explored. This could include providing other public benefits besides voter information, as well as political reform of other democracies and corporations.
\end{abstract}

* Mark Latham is a financial economist, and founder of VoterMedia.org.

Email: mark[at]votermedia.org

Voicemail: (604) 608-9779

Thanks for helpful comments from James McRitchie and Robert Hackett. 


\section{What is Votermedia?}

Votermedia is a participatory budgeting system that has evolved separately from the mainstream model of participatory budgeting pioneered in Porto Alegre, Brazil. ${ }^{1}$ Votermedia was originally conceived in 1988 at the University of California, Berkeley, for the purpose of informing and empowering corporate shareowners. ${ }^{2}$ Shareowners would vote to allocate a limited budget of corporate funds to competing providers of information about management policies and director election candidates. However, resistance by corporate boards, management and institutional investors has so far prevented any implementation in corporations.

Instead, votermedia has been implemented experimentally at student unions and municipalities in the Vancouver, Canada area since 2007. This paper describes those experiments and compares them with Porto-Alegre-style participatory budgeting, which we will abbreviate as "PAPB". An earlier paper, "Global Voter Media Platform" (at votermedia.org/publications), described experimental results up to 2009 , so to avoid repetition this paper will focus on results since that date.

The longest and most successful votermedia implementation so far is at UBC AMS, the University of British Columbia's student union (Alma Mater Society). Its 45,000 members pay mandatory dues that give the AMS an annual discretionary budget of about $\$ 2$ million. About $\$ 8,000$ of this has been used to fund votermedia. ${ }^{3}$ Whereas PAPB can fund a range of community services, votermedia is primarily designed to fund voter information. The funding allocation process takes the form of blog competitions, where voters decide how much each blog should receive. Other media besides blogs can also enter, but most entrants are blogs, so for simplicity I will refer to the contestants as blogs or bloggers.

Here are some quotes from video interviews of UBC students on their experience with votermedia (which they used to call voter-funded media or VFM):

Alex Lougheed, AMS VP Academic 2008-2009; later: Blogger, $\underline{U B C \text { Insiders: }}$

"It's been about four years with the project. I was involved on AMS Council when Mark first came to us with this idea, that he really wanted to get off the ground. At the time we figured, hey, this is a great idea, you know, we'll give it a shot, it's not going to cost that much, it's not a big deal. If it fails, it fails; if it succeeds, it succeeds. And it far surpassed any of anyone's expectations." votermedia.org/videos/2

\footnotetext{
${ }^{1}$ This paper is aimed at readers familiar with the Porto Alegre model. Those unfamiliar with it may want to read primers such as en.wikipedia.org/wiki/Participatory budgeting and its external links. Porto-Alegre-style participatory budgeting is now spreading to the USA and Canada, including an implementation now in progress in New York City (pbnyc.org) and a conference to which this paper has been submitted (pbconference.wordpress.com).

${ }^{2}$ An overview of VoterMedia was published in online newspaper The Tyee at thetyee.ca/Mediacheck/2012/01/27/Voter-Media/. The evolution of votermedia can be traced through the publications at votermedia.org/publications, especially the paper Voter-Funded Media: Governance Reform for Democracies \& Corporations. Recent publications on votermedia for corporations include Proxy Voting Brand Competition and Comments on SEC Proxy Concept Release.
}

${ }^{3}$ The AMS budget for VoterMedia awards was $\$ 8,000$ or more per year for the five years from 2006 through 2011. In the current 2011-2012 year, citing budget limitations, the AMS set their VoterMedia award budget to $\$ 1,000$. 
Bijan Ahmadian, AMS President 2010-2011:

"Votermedia has definitely made the election process more accessible. ...voter media really play an important role and have really been, you know, centre of gravity for voters to come together and discuss issues, discuss candidates, discuss their values, and give candidates an opportunity to respond, to engage with the voters, and it just feels more like a democracy than it used to..." votermedia.org/videos $/ 3$

Justin McElroy - Coordinating Editor, The Ubyssey:

"... does VFM work for students? I think yes. Does it increase campus discussion and student engagement? I think absolutely. Does it ensure that established media does a better job? Yeah. And are students and is this campus better off because of that? Well, absolutely." votermedia.org/videos/4

A sample of votermedia election coverage can be found at http://ubcinsiders.ca/category/elections/. An example of a policy critique is http://ubcinsiders.ca/2011/11/gage-south-campus-planning-with-no-plan/.

\section{Why Fund Media?}

The most obvious difference between votermedia and PAPB is that votermedia funds media while PAPB typically funds a range of municipal services, not including media. Why would citizens of a municipality want to fund media?

In section 2 of Global Voter Media Platform, I discussed why public funding for public interest media can help fill some important gaps that private sector media's incentives do not support. This is confirmed by authors such as Sunstein (1993, pp. 68-70):

"...freedom of choice, understood in market terms, is an incomplete solution when we are dealing with a public good, like national defence or clean air. Information about public issues has some of the characteristics of a public good, even in an era with diverse options. ... It is well known that if we rely entirely on free markets, we will not have enough national defines and our air will be excessively dirty. ... Because of the 'public good' features of information, no single person has a sufficient incentive to pay for the benefits that he receives. The result is simple and clear: The market will produce too little information."

Thus federal governments support media organizations like the CBC in Canada, PBS in the USA, and BBC in the UK. Likewise many university student newspapers are funded by mandatory fees. The same principles can be applied to argue for municipal government support of independent community media. However, I know of no municipal governments that do so. Perhaps it was not considered necessary when there were more local newspapers than there are today. 
But the changing economics of journalism are bringing this issue to the fore. The trend toward closing local newspapers has become all too familiar, as in this news item from December 19, 2011: "The concern stems from the recent decision by Metroland Media Group Ltd. to close six community newspapers that had been serving the communities of south, west, east and central Ottawa along with Nepean and Barrhaven. The closures come after Metroland purchased Performance Printing Ltd., which publishes newspapers in the same communities."

The positive side of changing economics is that the costs of distributing news have fallen dramatically, as more readers use the worldwide web. As a result, the amount of subsidy needed to support a given amount of public interest journalism is now relatively modest -- for example, the $\$ 8,000$ annual budget for votermedia at UBC AMS. With free electronic distribution, all we need to pay for is the journalists' time. Votermedia is designed to be highly competitive, creating as much public benefit as possible from limited funding. ${ }^{4}$

Democratic societies need public interest media to cover the government -- our elected leaders, public policies and their implementation. To do this effectively, the media need to be independent of government control. If media funding comes from the government, there is a danger of some control coming along with the money. For this reason, we can see why Porto-Alegre-style participatory budgeting (PAPB) would not be appropriate for funding public journalism. In PAPB, politicians and government employees are typically involved in screening the projects that voters will choose among, and in implementing the selected projects. This may be a reason why PAPB has not (to my knowledge) been used to fund political journalism.

The next section explains how votermedia enables voters to support competing media with minimal government involvement in the process, so as to empower journalists to be effective watchdogs for the public interest.

\section{Voter Funding Systems for Media}

In the UBC AMS implementations of votermedia, to minimize government control of voter information, there are few conditions on what blogs can enter the competitions. The AMS has sometimes merely required that contestants be UBC students, and that the blogs focus primarily on UBC, the AMS, and the student community.

PAPB has been implemented in a wide variety of ways -- see links from the global map at tiny.cc/pbmapping. To illustrate how PAPB funding allocation methods compare with votermedia, consider this simplified archetype: Suppose there is a $\$ 300,000$ budget to allocate, and the PAPB deliberation process has identified 10 potential projects, each of which would cost $\$ 100,000$ to implement. Citizens are then asked to vote for their preferred projects. Various voting rules may be used, but here is a typical setup: Each voter can choose up to 3 projects to support. The winning projects are the three with the most supporting votes. They are funded in the municipal budget, and then implemented by government staff.

\footnotetext{
${ }^{4}$ Another strategy for demonstrating the value of funding public journalism is for newspaper publishers to sponsor municipal votermedia competitions - see the paper Newspaper Sponsorship for Municipal VoterMedia at votermedia.org/publications.
} 
Votermedia's system for voting shares of the budget is fundamentally similar to the PAPB system, but has evolved to suit the needs of media competition. In particular, it empowers voters to determine and dynamically adjust the size of each budget slice. To see the similarity with PAPB, it is helpful to start with the first votermedia implementation, which was by UBC AMS in their January 2007 election:

The media award budget of $\$ 8,000$ was divided into 8 cash awards, ranging from a $1^{\text {st }}$ prize of $\$ 1,500$, down to $8^{\text {th }}$ prize of $\$ 500$. Any media could enter, whether student-run or not, for a $\$ 100$ entry fee (to help reduce ballot clutter from frivolous entries). There were thirteen entries, including blogs, print media, websites, and combinations of those formats. The media covered the election campaign, then students voted in the election on a ballot that included a new section for voting on the media contestants. Students could vote for as many media contestants as they wanted to support. The contestant with the most votes got the $1^{\text {st }}$ prize of $\$ 1,500$, the second highest vote-getter received the $2^{\text {nd }}$ prize of $\$ 1,400$, and so on. There was no requirement for the winners to continue blogging after the election, but some did continue, maintaining their readerships and reputations which could help them win awards in subsequent votermedia contests.

Whereas in PAPB, first, voters choose the projects and then the projects are implemented by the existing government; in votermedia, first, the bloggers choose what to write (freedom of the press) and then voters choose which bloggers to fund. Notice also the potential for profit and loss in the votermedia competition. Five of the entrants received no award, after paying the $\$ 100$ entry fee and working on their media content. Likewise, those who won awards were paid based on voting support, not based on the number of hours they worked.

Experimentation in subsequent years has resulted in a new voting system design that lets voters decide how to split up the award pool. Instead of a sequence of prizes defined in advance by an oversight committee, voters now choose a percent share for each media contestant. To keep it simple, the ballot offers a multiple-choice menu, usually $0 \%, 10 \%, 20 \%, 30 \%$ or $40 \%$.

The award calculation is not a simple average of voted shares. ${ }^{5}$ Instead, it is more like a median, with some adjustments to smooth out discontinuities, to ensure shares sum to $100 \%$, and to avoid concentrating the awards on too few blogs. (More explanations are at votermedia.org/faqs\#Voting.) Using a median rather than a mean rewards media that appeal to a broad cross-section of voters rather than to narrower interests or extreme views.

UBC AMS has typically run two votermedia competitions per year -- one in conjunction with their annual election in January-February, and one continuously through the school year. The election-linked competition is launched shortly before the election campaign, to encourage blog coverage of election candidates and their platforms. Blog funding is allocated by voters on a new section of the election ballot that lists the competing blogs. The continuous votermedia competition is hosted on the web at votermedia.org/ubc, where students can vote on blog funding at any time.

\footnotetext{
${ }^{5}$ For an explanation of why a simple average would not serve the public interest, see Global Voter Media Platform section 4, pages 7-8. Page 8 also outlines how using a simple average is equivalent to voucher systems such as those advocated by Ackerman \& Ayres (2002) and Nichols \& McChesney (2010).
} 
The two contests have relative strengths and weaknesses, so it seems ideal to continue running both. The election-linked version gets more voter turnout thanks to the publicity around the election, and has a more solid system for identifying unique voters. On the other hand, voters in continuous votermedia seem better informed about the blogs they are voting on; and the continuous feedback loop from media to voters back to media helps keep the bloggers on track and motivated (and voters informed) year-round.

We found that we could safely eliminate the entry fee in the continuous contest. It is not needed in continuous, because voting sorts the low-quality blogs to the bottom of the list, where clutter is less of a problem. Better still, the AMS has let the top 10 contestants from their continuous contest enter the election-linked contest with no entry fee, thus all but eliminating that barrier to entry.

Justin McElroy - Coordinating Editor, The Ubyssey:

"... people decide what they like for media every single day, simply based on what articles are the best out there, and what's illuminating them, and what's making them critically think, and what's making them argue with people on comments, right? And when you have continuous [votermedia] it forces people to be more engaged and to think about that. And therefore as media, continually post and continue to prove their relevance to students." votermedia.org/videos/5

\section{How to Include Votermedia in a Participatory Budgeting Process}

Votermedia has proven helpful in reaching out to inform and engage voters:

Jason Ng - Blogger, Social Capital:

"I think one of the challenges that UBC has always been dealing with over the past few years is: You've got a campus of 45,000 students; that's enough for a pretty big town. And everyone has different interests, everyone's from all kinds of places, and it's hard to bring that community together. And voter funded media has helped start that. It's helped bring together students that were not interested, necessarily, in student politics before. And helped them realize that a lot of the issues that affect UBC go beyond students who have a direct interest in politics, and really affect all the students that are part of the community for the years that they're here. And voter funded media has helped start that and helped generate a greater interest. I think we're seeing that reflected through better voter turnout, through better attendance at voter-related events. That hasn't happened before in previous years, partly because of the support that voter funded media has provided." votermedia.org/videos/2

This kind of community engagement is particularly important during elections. It is likewise important for the success of a process like participatory budgeting, which needs involvement and buy-in from as many community members as possible. This section outlines some ways that votermedia could be used to enhance a participatory budgeting process. 
Votermedia contests create an incentive for bloggers to connect with as many community members as possible. In order to benefit from this, a participatory budgeting process could fund a continuous votermedia competition from the start of its deliberation process. The blogs can help attract more participants (especially young people), and provide more forums for discussion of possible community projects to propose.

An effective continuous votermedia contest can run on as little as $\$ 30$ per day in awards. For example, our recent contest during the municipal election in Burnaby, British Columbia, ran on $\$ 20$ a day, and is currently continuing on $\$ 10$ a day - see the ballot at votermedia.org/burnaby and the award history at votermedia.org/burnaby/horserace. These were funded by VoterMedia.org and run informally without promotional links from city hall or its website. Promotion by the city would enhance effectiveness (as would an increased budget, of course). For a video discussion of implementing VoterMedia in municipal politics, see votermedia.org/videos/6.

VoterMedia.org is a nonprofit, open source project with no patents. We make our website available to communities at no charge, to create ballot pages for voting in their continuous votermedia contests. A community need only fund its awards, and even those funds need not flow through VoterMedia.org; they can be paid directly by the funding community to its bloggers. (We find that monthly payouts of accumulated daily awards is a practical schedule.) A new contest can usually be up and running the day after we receive the necessary information; new contestants can be added any time, usually by the next day.

We can see at least three ways of using votermedia to enhance a PAPB process, and any combination of them is feasible:

(a) Participatory budgeting processes typically have a budget for implementing the process itself. Some of this is used for citizen outreach - publicizing the process and encouraging citizen participation. Some of this budget could be used to fund a continuous votermedia contest that starts early in the information/outreach stage. The competing blogs can encourage more public discussion of ideas and options for projects to include in the participatory budget.

(b) Most participatory budgeting processes culminate in a vote by citizens to choose which projects to fund. This vote is a good opportunity to add a one-time votermedia contest in addition to the continuous contest proposed above. In a separate section from the main PAPB project vote, the one-time contest would let voters allocate another chunk of funds to bloggers. This would specifically encourage them to reach out to participants who will vote in PAPB. At UBC, the AMS has funded such one-time contests (election-linked) in amounts varying from $\$ 1,000$ to $\$ 8,000$.

(c) Citizens could consider funding future votermedia implementations, as one of the projects competing for funds in the participatory budgeting process. This could be especially helpful for voter engagement and information in the next municipal election. The competitive design of votermedia seems to generate considerable public benefit per dollar. 


\section{Competitive Markets for Public Goods}

How might participatory budgeting evolve if it includes votermedia and is implemented by a growing number of municipalities? No doubt the process of experimentation will continue, as various municipalities try implementing it in various ways. We will learn which ways work better, and build on them. This section of the paper speculates on possible developments.

Among the distinguishing features of votermedia are that it is competitive and entrepreneurial. The potential for profit and loss was noted in section 3 above. The contests are easy to enter. Student comments include:

Neal Yonson, Blogger, UBC Insiders:

"... because all this competition really encourages good information and diversity of viewpoints on whatever we're covering, and in this case it's student society elections. So it keeps us busy, and keeps us definitely motivated and competitive." votermedia.org/videos/1

Justin McElroy - Coordinating Editor, The Ubyssey:

"It ensures that people do their best, and try to break the stories first, and get that information out there." votermedia.org/videos/4

Alex Lougheed, AMS VP Academic 2008-2009; later: Blogger, UBC Insiders:

"One of the great things about VFM is that it's self-regulatory. It's a very free market approach to solving a lot of the problems with media today." votermedia.org/videos/1

If these design features continue to provide high levels of public benefit per funding cost, then citizens may choose to increase the funding for votermedia. Contestants may then have enough resources to provide other public goods besides information, and use their blogs to publicize the goods they are providing. As noted in Global Voter Media Platform: "They might provide other public benefits such as consumer information, public policy research, antitrust monitoring, funding the creative commons, headhunting for election nominees, review of legislation, and other services now provided by governments."

Votermedia gives competing people (or teams) an incentive to invest in their reputations for serving the public. Reputation is important because it is difficult for most voters to judge the quality of information in particular, and other public goods as well. Quality becomes easier to assess with a larger sample size of outcomes, which can be generated by a votermedia team competing for multiple years and serving multiple voter communities. So we can expect such teams to grow in size and scope, in order to build their brand reputations.

Successful growth and strengthening of participatory budgeting with votermedia in municipal governments could lead to this movement spreading to other types of democracies such as associations, labor unions, credit unions, co-ops and countries, as well as to corporations. There seems to be considerable potential for reducing corruption (and other inefficiencies), thus greatly improving public welfare. 


\section{References}

Ackerman, B., \& Ayres, I. (2002). Voting with Dollars: A New Paradigm for Campaign Finance. New Haven, CT: Yale University Press.

Latham, M. (2007a). Proxy Voting Brand Competition. Journal of Investment Management, 5(1), 79-90. Available at votermedia.org/publications.

Latham, M. (2007b). Voter-Funded Media: Governance Reform for Democracies and Corporations. Working paper. Available at votermedia.org/publications.

Latham, M. (2009). Global Voter Media Platform. Working paper. Available at votermedia.org/publications.

Latham, M. (2010). Comments on SEC Proxy Concept Release. Retrieved December 27, 2011 from www.sec.gov/comments/s7-14-10/s71410-52.pdf.

Latham, M. (2012). Newspaper Sponsorship for Municipal VoterMedia. Working paper. Available at votermedia.org/publications.

Nichols, J., \& McChesney, R. W. (2010). The Death and Life of American Journalism: The Media Revolution that Will Begin the World Again. Philadelphia: Nation Books.

Sunstein, C. (1993). Democracy and the Problem of Free Speech. New York: The Free Press. 